\title{
DOSSIER
}

\section{España y la I Guerra Mundial Cien años después}

\author{
Spain and the First World War \\ One hundred years later
}

PRESENTACIÓN

\section{Coordinado por Francisco J. Romero Salvadó}

DOI. https://doi.org/10.20318/hn.2017.3490

El 28 de junio de 1914, el heredero al trono austro-húngaro, el Archiduque Francisco Fernando de Habsburgo-Lorena, y su esposa, la Duquesa Sofía de Hohenberg, fueron asesinados en Sarajevo (Bosnia) por Gavrilo Princip, miembro de un grupo radical nacionalista que luchaba por la liberación de Bosnia del dominio austriaco y su integración a Serbia. Magnicidios no eran novedad en una era que habían perecido a causa de atentados terroristas entre otros el Zar Alejandro II de Rusia (1881), la Emperatriz Isabel de Austria (1898), el Rey Humberto I de Italia (1900), el Presidente de los Estados Unidos William Mckinley (1901), el Rey Carlos I de Portugal y su hijo y heredero Luis Felipe (1908). En medio quedaban un número elevado de intentonas fallidas como la bomba arrojada en la Calle Mayor de Madrid sobre la carroza del Rey Alfonso XIII el día de su boda con la princesa inglesa Victoria Eugenia de Battenberg (1906). Sin embargo, el asesinato del Archiduque Francisco Fernando no fue un mero atentado más sino un suceso de excepcional importancia histórica; el desencadenante de un conflicto sin parangón entre las grandes potencias europeas divididas desde hacía décadas en dos bloques rivales, por un lado los imperios centrales (Alemania y Austro-Hungría) y por el otro, la Entente entre Gran Bretaña, Francia y Rusia.

En el verano de 1914, la mayoría de las elites gobernantes confiaban que una decisiva victoria tras una campaña relativamente breve serviría para silenciar los crecientes movimientos de protesta y disidencia doméstica. Sin embargo, ni la guerra fue breve ni frenó el avance de la política de masas. El armisticio en noviembre de 1918 no pudo borrar los efectos de cuatro años de conflicto devastador. El cataclismo bélico, la sangría humana y la dislocación socio-económica hicieron imposible dar marcha atrasa al fatídico reloj de la historia: el universo socio-político e ideológico dominante en 1914 estaba definitivamente finiquitado. Al principio de la contienda, monarquías de origen divino y feudal eran todavía la pieza central de la sociedad civil y política. Cuatro años después, las coronas de buena parte 
del continente junto a su tradicional legitimidad habían sido barridas no tanto por la suerte de las armas en el campo de batalla sino por la movilización de las masas. La Gran Guerra hizo posible el desmoronamiento de los antiguos imperios (alemán, austro-húngaro, ruso y otomano), la liquidación de las antiguas fronteras históricas dando lugar al nacimiento de nuevos estados, el afianzamiento de nuevas potencias extra-europeas como los Estados Unidos y el Japón y, por último, alumbró nuevas doctrinas de ambición totalitaria como el comunismo y el fascismo. La esperanza acariciada por muchos como el escritor H. G. Wells que se trataba de la guerra definitiva para erradicar de una vez por todas las guerras (The war that will end war) fue una falacia de dimensiones similares al tan cacareado fin de la historia anunciado por Francis Fukuyama en 1992 tras la caída de la Unión Soviética.

La Gran Guerra ha sido siempre sujeto primordial de estudio, investigación y debate. En el caso de muchos países, por razones más que obvias, es una parte intrínseca de su memoria histórica. En el Reino Unido, referencias están presentes por doquier en la vida cotidiana: columnas, placas, monumentos, etc. Desde que fue establecido en 1919 por el Rey Jorge V, el 11 de noviembre de cada año se conmemora con toda solemnidad el llamado Poppy Day (Día de la Amapola). Desde miembros de la casa real hasta presentadores de televisión, los británicos, casi sin excepciones, lucen pequeñas amapolas rojas de plástico en las solapas que simbolizan el recuerdo de los sacrificios de las fuerzas armadas en tiempos de guerra, en particular las horribles pérdidas de la I Guerra Mundial. Es un día de desfiles militares, espacios culturales, ofrendas florales, siendo la más importante la del monumento a los caídos (Cenotafio) presidido por la reina, y de celebraciones solemnes como el servicio religioso de la Abadía de Westminster donde se ubica el llamado Campo de la Memoria.

No es sorprendente que la Gran Guerra no ocupe el mismo lugar preminente en España, ausente de los campos de batalla, que en los países beligerantes. Tras 40 años de dictadura donde la historia había sido sistemáticamente manipulada y articulada para servir de propaganda oficial del estado, el foco de atención tanto de académicos como de la población en general se concentró en aquellos episodios más cercanos en el tiempo y de mayor impacto social: el experimento democrático de la II República, la brutal guerra fratricida e incivil (en frase de Miguel de Unamuno) y el largo régimen presidido por el General Francisco Franco. El resultado fue la consolidación de una paradoja: la ausencia de un volumen significante de monografías, proyectos académicos e investigativos sobre el impacto de la Gran Guerra en España a pesar del reconocimiento por parte de historiadores, sociólogos y economistas de su crucial importancia para comprender el curso de su historia contemporánea. Como expuse en un trabajo significativamente titulado en inglés, Foundations of Civil War (2008), las semillas de la tragedia de 1936 se sembraron durante el proceso de polarización y crisis final del estado liberal (1916-1923). Afortunadamente, la relativa deficiencia de estudios sobre España y la Gran Guerra se ha ido corrigiendo durante los últimos años y el centenario, en la que debe enmarcarse este dossier, ha servido para estimular su investigación y debate.

Cuando las hostilidades estallaron en el verano de 1914, el gobierno conservador presidido por Eduardo Dato rápidamente declaró la neutralidad oficial de España en el conflicto internacional. Tal posicionamiento enseguida recibió el apoyo de prácticamente todos los sectores sociales y políticos del país. Mantenida a capa y espada hasta el día del armisticio, la neutralidad salvó a España de la hecatombe humana y material que habría supuesto la beligerancia pero no pudo aislarla de sus devastadores efectos. El impacto de la contienda traspasó las fronteras de los países beligerantes y también alcanzó a los países neutrales con efectos afines a un terremoto socio-político. 
La neutralidad no impidió la intervención o actividades de las grandes potencias en su territorio. Por el contrario, España se convirtió en un teatro menor de operaciones con la consiguiente merma de su soberanía, libertad de comercio y control sobre costas y aguas territoriales. Dentro de un primer bloque de artículos sobre política exterior, nadie mejor que Jean-Marc Delaunay para analizar el impacto del conflicto en las relaciones franco-hispanas, debido a su extenso conocimiento de este campo. A diferencia de los trabajos investigativos que conforman el resto de este dossier, se trata de un ensayo de reflexión y recopilación de prácticamente el trabajo de toda una vida. Habiendo ya afirmado en alguno de sus trabajos anteriores que en términos económicos, España había trabajado para la victoria de los Aliados debido a la masiva movilización de sus recursos materiales, Delaunay concluye que la relación básica entre los dos países, basada en cierto sentimiento de tutelaje diplomático y cultural que podía llegar a la prepotencia por parte del vecino galo, no sufrió ningún cambio decisivo. No obstante, la relación franco-española atravesó momentos difíciles auspiciados tanto por rivalidades coloniales en Marruecos como por la difusión por parte de sectores germanófilos de los peores estereotipos de Francia: su intolerancia anticlerical, su arrogancia imperialista y cultural, su acogida de anarquistas y enemigos del régimen español, etc. El punto culminante de estas tensiones tuvo lugar durante el verano revolucionario de 1917 cuando nacionales franceses fueron acusados por las autoridades españolas de haber fomentado la subversión.

Otra destacada especialista en relaciones internacionales, María Lola Elizalde, analiza las relaciones con la otra gran potencia occidental: Gran Bretaña. Debido a sus grandes inversiones económicas así como el valor estratégico de su bastión de Gibraltar, los círculos dirigentes británicos consideraban como un objetivo fundamental el apoyo de España durante el conflicto. Basado en un análisis exhaustivo de las fabulosas fuentes primarias del National Archives (el antiguo Public Record Office), este artículo explora detalladamente el arduo trabajo del cuerpo diplomático británico por influenciar la actitud del voluble soberano español y de sus diferentes gobiernos durante una era de creciente convulsión interna. En gran medida, el énfasis se centra en el año clave de 1917: en la primavera de este año el Ministerio Romanones consideró la ruptura con Alemania, lo que viendo el ejemplo norteamericano podría haber arrastrado al país a la guerra, y después en el verano, el embajador británico (Arthur Hardinge) tuvo que hacer esfuerzos colosales para distanciarse de un movimiento revolucionario dominado por los simpatizantes de la Entente en España. Después de todo a pesar de las simpatías por los Imperios Centrales de amplios sectores del régimen, la estabilidad de la monarquía, visto además el reciente caso ruso, era apreciada como fundamental para los vastos intereses comerciales británicos. Sus esfuerzos, no sin meses de procrastinación por parte hispana, se saldaron con la ratificación en diciembre de 1917 del Acuerdo Cortina (bautizado con el nombre del principal negociador español, el Marqués de Cortina), que garantizaba el suministro a Gran Bretaña del vital suministro de hierro para su esfuerzo bélico a cambio de carbón y otros productos industriales. Por encima de todo, este artículo expone el tremendo pragmatismo, no exento de cierto maquiavelismo, de la diplomacia británica. Es decir, su búsqueda del apoyo español sin llegar a ofrecer mucho a cambio: desde luego no en principio a devolver Gibraltar y suspicacias ante la posibilidad de hacer concesiones en Marruecos debido al temor que la inepta administración española pudiese mantener el control y obligase a Francia, no olvidemos que era su ahora socio y aliado, a intervenir liquidando de un plumazo las precauciones británicas de evitar su presencia en la costa de Marruecos.

Este primer bloque concluye con el artículo sobre Alemania de Anne Rosenbusch, una joven autora cuya impactante investigación ha actualizado, ampliado y revisado la tesis clásica de Ron M. 
Carden, German Policy Toward Neutral Spain, 1914-18 (1987). Basado en un vasto número de fuentes documentales de archivos alemanes pero también británicos, este artículo demuestra la increíble proeza de la diplomacia germana de mantener intacta durante los cuatro años de conflicto la neutralidad oficial española a pesar de una realidad geográfica y económica que la situaba firmemente en la órbita de los países aliados. Dos aspectos son analizados en profundidad. En primer lugar, en el campo de la propaganda, Rosenbusch sugiere que el caso de España demuestra que el General Erich Ludendorff, el aclamado jefe del estado mayor alemán, se equivocaba al sugerir que perdieron la batalla por el alma de los países neutrales. De hecho, los esfuerzos de Alemania para influir la opinión pública española precedieron y tuvieron mucha mayor envergadura que aquellos de los Aliados. Los altos costes de la prensa, debido a la carestía del papel, facilitaron que unas 500 publicaciones nacionales y locales cayeran bajo su influencia. No se trataba solamente de aquellas de marcado signo conservador y monárquico sino también de anarquistas y republicanas. De esta forma, cualquier desafío a la neutralidad era tildada de traición por la prensa patriótica de derechas y de intento de arrastrar al proletariado a una guerra imperialista por las izquierdas. Con este formidable bloque propagandístico, Berlín pudo influenciar a un amplio arco de la opinión pública y atacar a cualquier gobierno hostil a sus designios, caso del Ministerio Romanones (diciembre de 1915 - abril de 1917) que consideró alienarse más claramente con la Entente. Finalmente, este artículo también profundiza e ilumina la ya bien estudiada área de la guerra de espías en España. Bajo la dirección última de su embajador, Príncipe Maximilian von Ratibor, Alemania puso en marcha una vasta campaña de inteligencia. Sus redes de espionaje alistaron los servicios de todo tipo de personajes (prostitutas, camareros, bailarinas, agentes de policía, etc.) para informar sobre las rutas y salidas de buques mercantes para facilitar la acción de los submarinos. El servició de inteligencia alemán también se infiltró en grupos anarquistas para sabotear la industria que producía para el esfuerzo bélico aliado. El éxito de la intervención alemana en España desembocó en una paradoja: los Aliados en general, y Gran Bretaña en particular, se afanaban en apoyar el régimen español y repudiaban cualquier alineamiento con las izquierdas que en general ideológicamente se identificaban con su causa, mientras al mismo tiempo Alemania, gran adalid de la España conservadora, fomentaba el desorden y la subversión revolucionaria.

El impacto cultural de la Gran Guerra constituye el segundo bloque de este dossier. Este campo, relativamente ignorado por la historiografía durante mucho tiempo, ha experimentado en los últimos años una auténtica explosión de estudios entre los que destaca en el caso de España, la original perspectiva de los trabajos de Maximiliano Fuentes Codera. El consenso inicial entorno a la neutralidad se fracturó a medida que progresaba el conflicto. La opinión pública comenzó a polarizarse al identificarse con los principios que los bandos combatientes parecían simbolizar. Fue tal el nivel de pasión que en palabras del historiador norteamericano Gerald Meaker (A Civil War of Words, 1988) llegó a adquirir la cualidad moral de casi una guerra civil dialéctica que anticipaba la que estallaría 20 años después. Contemporáneos de los hechos revelan que las filias y las fobias rompieron matrimonios y amistades, causaron trifulcas en el trabajo y en tertulias. Aunque no sin importantes excepciones, la aristocracia, la alta burguesía, la corte, los latifundistas, los oficiales del ejército y la iglesia eran germanófilos. Para ellos, los Imperios Centrales representaban valores fundamentales (tradición, autoridad, orden social jerárquico, etc.) que ansiaban preservar. Por el contrario, la gran mayoría de los intelectuales, las profesiones liberales, y los dirigentes obreros en el movimiento socialista se identificaban con los Aliados y en particular con la anticlerical y republicana Francia, modelo de país moderno y secular que deseaban. Tradicionalmente, la mayoría de estudios limitaba esta pugna 
ideológica a las elites culturales, políticas y socio-económicas del país pues la mayoría de la gente, bien por ignorancia o por falta de interés, ni comprendía ni se preocupaba por el curso de la contienda. Por el contrario, la contribución de Fuentes Codera a este dossier desmonta aquella tesis. En primer lugar, este artículo expone la centralidad que los intelectuales tuvieron en el desarrollo de las diferentes posiciones sobre la neutralidad. Aunque la mayoría se decantaron por el aliadofilismo, todos tenían en común la esperanza que la influencia de Europa podría regenerar y sacar a España de su decadencia. Segundo, habiendo analizado a fondo el impacto de la guerra en las comarcas gerundenses, este autor concluye que las divisiones ideológicas se reprodujeron también a nivel local. De este modo, la crispación dominó la vida cotidiana y centralizó el debate en ciudades y pueblos. En este contexto, los llamados "intermediarios culturales" (maestros, profesores) jugaron un papel fundamental en convertir la cuestión de la neutralidad en uno de los ejes centrales de la política local.

Cerrando esta sección dedicada a la historia cultural, Gregorio Alonso, autor de reputación internacional en este campo, se centra en el impacto de la Gran Guerra en la renovación de los discursos de dos de las principales voces de la germanofilia en España: la Iglesia y el movimiento tradicionalista, en particular su más fructífero pensador, Juan Vázquez de Mella. Para los principales sectores eclesiásticos del país, el mismo estallido del conflicto fue interpretado como consecuencia de los procesos paralelos de modernización socio-económica y secularización que a lo largo del Siglo XIX había erosionado los cimientos morales de la civilización occidental y que se asociaban con la nefasta hegemonía de la protestante Inglaterra y la anticlerical Francia que además tantos agravios históricos habían causado a España (Guerra de Independencia, Gibraltar, etc.). La Iglesia percibía, por consiguiente, una victoria de los Imperios Centrales como una forma radical pero necesaria de frenar esa tendencia. En su segunda mitad, este artículo examina como Vázquez de Mella vio en la guerra una oportunidad para la renovación de los principios ideológicos del Carlismo, un movimiento en clara decadencia tras su derrota militar en 1876. Irónicamente, su férrea identificación con Alemania contribuyó a magnificar las tensiones internas y a liderar un cisma contra el aliadófilo pretendiente, Don Jaime. "Afectos caprichosos", título de este artículo, era la interpretación que daba Vázquez de Mella a la torpe impresión que muchos españoles tenían por Francia como símbolo de progreso. En su nostalgia por la tradición, Mella argumentaba en favor de una nueva alianza con Alemania, el evidente sucesor del Sacro Imperio Romano Germánico, cuya realidad bajo los Habsburgo en el Siglo XVI había resultado en una era de gloria para España.

El bloque final de este dossier se centra en el impacto de la Gran Guerra a nivel doméstico. Autor de dos monografías sobre este tema, Francisco J. Romero Salvadó centra su atención especialmente en el decisivo año de 1917: momento de máxima polarización en torno a la neutralidad saldado con la intervención de Alfonso XIII y la destitución del Ministerio Romanones (abril), insubordinación de los sindicatos castrenses conocidos como Juntas Militares de Defensa, (junio), establecimiento de una asamblea de diputados disidentes en Barcelona (julio), huelga general obrera (agosto) y finalmente derribo del Ministerio Dato por el ejército y fin del turno de los dos partidos dinásticos (octubre). El caso de España no es analizado como un caso excepcional sino como la versión regional de la crisis de modernidad que afectó a toda Europa. Es decir, un largo periodo de modernización socio-económica, avance tecnológico y progreso cultural que facilitó la llegada de la sociedad y política de masas. Dentro de estos parámetros, la Gran Guerra aceleró el proceso de decadencia y quiebra del orden monárquico y elitista hegemónico hasta 1914. Siguiendo la pauta de estudios comparativos, este artículo explora semejanzas y diferencias con Rusia, encarnación del triunfo 
revolucionario en 1917. La conclusión es que Rusia constituyó un caso excepcional. La hecatombe humana, la convulsión demográfica y el trastorno socio-económico produjeron temporalmente las condiciones necesarias para el triunfo de la revolución: la caída del zarismo en marzo y luego de su heredero el gobierno provisional en noviembre. Sin embargo, estas condiciones no existieron en España donde la relativa cohesión de las clases gobernantes y sobre todo la astucia del Ministerio Dato no podía contrastar más con el relativo amateurismo de los principales agentes de la revolución en ese momento, el movimiento socialista. Sin embargo, más que de fracaso, el desenlace del ciclo revolucionario de 1917 debe analizarse como un momento álgido, pero en ningún caso final, de la mencionada crisis de modernidad y de un proceso paralelo de conflictividad social y violenta realineación política.

Los dos artículos siguientes exploran el impacto de la Gran Guerra en los dos principales epicentros de conflictividad social en España: Cataluña y Andalucía. En el caso de la primera, en los albores del estallido de las hostilidades, Barcelona, la gran metrópolis industrial del país, presentaba una combinación letal: una masa proletaria con una tradición sin parangón en España de organización y militancia, unas clases medias seducidas por el nacionalismo catalán, una intransigente clase patronal en permanente estado de pánico ante la fuerza sindical y una guarnición sobredimensionada, inquieta y siempre en ciernes de tomar el control del orden público. Irónicamente, todos tenían algo en común: el desprecio y la desconfianza hacia la administración central en Madrid. Si la capital catalana era, por consiguiente, un barril de pólvora en 1914, la Gran Guerra sirvió de espoleta. En ninguna otra ciudad española, el contraste social llegó a adquirir niveles tan obscenos: ostentación y opulencia de una burguesía enriquecida de la noche a la mañana por la incesante demanda exterior frente a la miseria del proletariado abocado a una carrera contrarreloj para mantener su nivel de vida bajo los efectos de una inflación galopante que encarecía alimentos, combustible y vivienda. El resultado fue el recrudecimiento de la tradicionalmente ya violenta lucha de clases.

Autor de estudios monográficos sobre el nacionalismo y el anarco-sindicalismo catalán, Angel Smith investiga el crucial impacto de la Gran Guerra en la evolución de ambos movimientos. El catalanismo político, representado por la Lliga Regionalista de Catalunya, alcanzó una nueva fase de madurez, hegemonía a nivel local e incluso temporalmente su gran objetivo de tener un peso fundamental a nivel estatal. Sin embargo, sus mismas contradicciones internas (conservadurismo de sus elites dirigentes vis-à-vis reformismo de sus bases) le llevaron al fracaso final de ser el gran artífice de la modernización democrática de España. De este modo en dos momentos decisivos propiciados por la Gran Guerra acabaría abandonando su papel de vanguardia de las fuerzas en favor de la reforma: disolución de la asamblea a cambio de representación en el gobierno en noviembre de 1917 y abandono del proyecto de autonomía en febrero de 1919 en busca de una alianza con el ejército para suprimir la percibida amenaza revolucionaria representada por la Confederación Nacional del Trabajo, el sindicato anarco-sindicalista cuyo crecimiento vertiginoso durante los años de la guerra se debía a su identificación con las inquietudes del proletariado y tras 1917 con la esperanza revolucionaria estimulada por el triunfo Bolchevique en Rusia.

Especialistas en el agrarismo andaluz, Francisco Cobo y Teresa Ortega, estudian el impacto de la Gran Guerra en el otro gran epicentro de protesta social en España. Su contribución consiste en un original estudio comparativo con el caso de Italia. En este contexto, se analizan dos periodos paralelos en el tiempo: el Biennio Rosso (1918-1919) en Italia y el Trienio Bolchevique en España (1918-1920). A 
consecuencia del proceso de modernización productiva y repunte inflacionista causado por la Gran Guerra, tanto el Po Valley como Andalucía vivieron un periodo extraordinario de agitación social y conflicto huelguístico. Los radicalizados jornaleros andaluces y sus homólogos, los braciantti italianos, se afiliaron en masa a sindicatos agrícolas y consiguieron en gran medida imponer sus condiciones laborales. Atemorizados por lo que percibían como una revolución inminente de signo comunista, la oligarquía agraria, apoyada por los pequeños y medianos propietarios, comenzaron a desertar en masa el sistema parlamentario y liberal que parecía incapaz de defender con la contundencia necesaria el orden social. En este proceso, acabaron apoyando soluciones de tipo autoritario y violento (squadristi fascistas en el Po Valley y Somatenes y Guardias Cívicas en Andalucía) que facilitarían la llegada al poder de Benito Mussolini en octubre de 1922 y del General Miguel Primo de Rivera un año más tarde.

Finalmente, este dossier concluye con un artículo sobre el impacto de la Gran Guerra en el Protectorado de Marruecos. Aún reciente la memoria de la sangría del desastre de 1898 , las clases humildes no estaban dispuestas a servir de carne de cañón de una nueva guerra colonial debido a que no podían pagar su redención en metálico (las 1.500 pesetas que libraban a los hijos de la burguesía de ir al ejército). Además, a diferencia de los vínculos históricos con Cuba, la nueva campaña era percibida, y no sin razón, como una aventura imperialista que se activaba para proteger los intereses capitalistas de las compañías mineras. Por consiguiente, la movilización de tropas en julio de 1909, para más inri muchos de ellos reservistas, tras el rebrote de violencia en aquel territorio, desencadenó masivas protestas populares y el anuncio de una huelga general que se tradujo en Barcelona en una semana de barricadas, saqueo y quema de edificios religiosos y violenta represión militar. Tras la creación del Protectorado en 1912, las autoridades españolas intentaron continuar su control de la zona por medio de una guerra de baja intensidad donde primaba más el soborno de los cabecillas locales que el combate. Como explica Pablo La Porte, especialista sobre el colonialismo español en Marruecos, la inmensa repercusión de la Gran Guerra en el Protectorado hizo imposible la continuidad de esa política de penetración relativamente pacífica. En primer lugar, el movimiento corporativo representado por las Juntas Militares de Defensa también llegó al Protectorado con el resultado de incrementar las tensiones con los llamados africanistas (oficiales que habían elegido perseguir su carrera militar en Marruecos) con consecuencias contraproducentes para la dinámica de una efectiva acción de control colonial. Y segundo, el Marruecos español sirvió de plataforma de operaciones de agentes alemanes quienes pudieron financiar y armar la insurrección en la zona francesa con la pasividad de muchos oficiales españoles y el obvio detrimento de las relaciones con las autoridades coloniales galas. Tras la Gran Guerra España iba a pagar un fuerte precio: una insurrección en gran medida facilitada por el previo armamento alemán de las guerrillas y sin la crucial alianza de Francia. El resultado fue el fatal desastre de Anual en el verano de 1921; un golpe letal al desprestigiado estado de la Restauración en un momento que su hegemonía sucumbía ante la creciente radicalización política y la violencia social en que España, como gran parte de Europa, se veía abocada tras el armisticio.

En conclusión, el objetivo de los artículos recopilados en este dossier es contribuir al estudio del impacto y legado de la Gran Guerra en España; un capítulo fundamental de su historia que hasta tiempos recientes ha permanecido relativamente olvidado. Mucho más que un mero cataclismo bélico, el conflicto constituyó un agente de modernización y revolución contra el statu quo de 1914. El armisticio silenció (durante dos décadas) las armas en el campo de batalla pero dio lugar a una era sin precedentes de convulsión socio-económica y radicalización política; era que muchos autores describen de guerra civil europea donde la guerra fratricida de 1936 uno fue de sus capítulos más cruentos. 